\title{
Knowledge practices in design: The role of visual representations as 'epistemic objects'
}

Article

Accepted Version

Ewenstein, B. and Whyte, J. (2009) Knowledge practices in design: The role of visual representations as 'epistemic objects'. Organization Studies, 30 (1). pp. 7-30. ISSN 01708406 doi: https://doi.org/10.1177/0170840608083014 Available at https://centaur.reading.ac.uk/11980/

It is advisable to refer to the publisher's version if you intend to cite from the work. See Guidance on citing.

Published version at: http://oss.sagepub.com/cgi/reprint/30/1/07

To link to this article DOI: http://dx.doi.org/10.1177/0170840608083014

Publisher: SAGE Publications

All outputs in CentAUR are protected by Intellectual Property Rights law, including copyright law. Copyright and IPR is retained by the creators or other copyright holders. Terms and conditions for use of this material are defined in the End User Agreement.

www.reading.ac.uk/centaur

\section{CentAUR}


Central Archive at the University of Reading

Reading's research outputs online 


\section{Knowledge practices in design: The role of visual representations as 'epistemic objects'}

Boris Ewenstein and Jennifer Whyte

Please reference as:

Ewenstein, Boris and Whyte, Jennifer (2009) "Knowledge practices in design: The role of visual representations as 'epistemic objects'." Organization Studies 30(1): 7-30.

The final, definitive version of this paper has been published in Organization Studies, 30/01, January 2009 by SAGE Publications Ltd, All rights reserved. (C) This is the accepted version, posted by the second author on the University of Reading website under the terms of the contributor agreement. 


\begin{abstract}
We use a detailed study of the knowledge work around visual representations to draw attention to the multi-dimensional nature of 'objects'. Objects are variously described in the literatures as relatively stable or in-flux; as abstract or concrete; and as used within or across practices. We clarify these dimensions, drawing on and extending the literature on boundary objects, and connecting it with work on epistemic and technical objects. In particular, we highlight the epistemic role of objects, using our observations of knowledge work on an architectural design project to show how, in this setting, visual representations are characterised by a 'lack' or incompleteness that precipitates unfolding. The conceptual design of a building involves a wide range of technical, social and aesthetic forms of knowledge that need to be developed and aligned. We explore how visual representations are used, and how these are meaningful to different stakeholders, eliciting their distinct contributions. As the project evolves and the drawings change, new issues and needs for knowledge work arise. These objects have an 'unfolding ontology' and are constantly in flux, rather than fully formed. We discuss the implications for wider understandings of objects in organizations and for how knowledge work is achieved in practice.
\end{abstract}

Keywords: boundary objects, practice, collaborative knowledge work, epistemic objects, technical objects, visual representations 


\section{Introduction}

In recent social research there is renewed theoretical interest in the concept of practice, with some authors even identifying a 'practice turn' in contemporary theory (Schatzki, Knorr Cetina and von Savigny 2001). Simultaneously there is a call for more empirical research into actual working practices (Heath and Button 2002: 159-160; Heath, Knoblauch and Luff 2000: 302). In the context of debates around the knowledge economy or the knowledge society (e.g. Beck 1992; Giddens 1990), the question emerges as to how knowledge-intensive work is actually achieved in practice.

Practice-based theorizing, as well as anthropological studies of work contexts and social studies of science and technology, have influenced a wider resurgence of interest in objects within organizational studies (Engeström and Blackler 2005). A focus on objects brings practice into view and the rich material contexts and dense social relations in which production takes place. An analytical interest in objects also reveals their centrality to the various processes and practices of learning and knowing. Bechky (2003), for instance, argues that objects such as engineering drawings and machines in production 'embed knowledge' and are therefore useful in problem solving. Yet despite agreement over the centrality of artifacts to both thought and action, the nature of objects of work is seen as complex and ambiguous (Engeström and Blackler 2005). It seems the more objects are studied, the more diffuse they become, even as their centrality to organizational activity is acknowledged.

In the existing literature, the emphasis has been placed on the role that the objects play rather than on the nature of the objects themselves. Most commonly the focus is on objects in their role as boundary objects mediating interaction between epistemic communities within organizations. The objects discussed in this literature range from abstract objects such as 'California' (Star 1989) to the more concrete: sketches (Henderson 1991; Henderson 1999); project management tools (Sapsed and Salter 2004); virtual prototypes (D'Adderio 2001; D'Adderio 2003); timelines or Gantt charts (Yakura 2002), as well as drawings and charts, schedules and tables, machines and parts (Carlile 2002). Writers are less concerned with the essence of the objects themselves and more with the 'question of boundary management when novelty arises' (Carlile 2004: 566).

Accepted version, final publication: http://oss.sagepub.com/cgi/content/abstract/30/1/07 
The internal characteristics of boundary objects such as their representational capacity are discussed on a general level, but they are not explained. This is understandable as the object's effectiveness is defined by the context in which it needs to perform. However, this focus on boundaries and communities more than the nature of the object has a number of consequences.

One consequence is that the object itself is seen as stable, and another is that the focus is on its use across rather than within practices. There are a set of unanswered questions about how different types of artifacts act (more or less effectively) as boundary objects. When and why do they become boundary objects and what other roles do they play? Carlile (2004) addresses the effectiveness of boundary objects in new product development, but we know little about the roles that objects play in other contexts for knowledge work. Hence, these questions suggest the need for further empirical work to understand how different types of objects become useful in organizational knowledge practices. As part of understanding organization as it happens we need 'an appreciation of the nexus of material arrangements in which its practices proceed' (Schatzki, 2006). Orr's (1996) ethnographic study of the working practices of photocopier technicians, celebrated in a recent issue of Organization Studies (Tsoukas 2006), has been suggested as a model for such thick descriptions of work and 'increased ethnographic attention to knowledge and technical work' (Bechky 2006).

Through observation of work in an architectural firm, this paper develops one account of knowledge practices focused on the role of visual representations as objects. Our theoretical approach draws on a cultural approach to organizational knowledge and learning (Yanow 2000). This approach has a particular interest in the development of situated meaning. It contrasts with the wider discourse about communities of practice (in which the idea of a boundary object is mobilized), which 'risks being taken as privileging acts over or to the exclusion of linguistic and physical artifacts' (Yanow 2000). From this perspective we can both see acts, conversations and artifacts in a cultural setting and acknowledge the differences between the conceptual design work that we study and other contexts studied in literatures.

There is something distinct about the objects in and of themselves that make them key to knowledge development and innovation. To address this, we draw on a parallel, 
but previously unconnected, stream of work on objects in their roles as epistemic objects and technical objects. This work, in the historical and sociological studies of science, sees such objects as fundamental to experimental systems. Epistemic objects are abstract in nature: they are the objects of inquiry and pursuit. Hence, they are characterized by lack and incompleteness. As they appear in temporary instantiations, they are defined at once by what they are and what they are not (or not yet). In the context of science, examples include physical structures, chemical reactions and biological functions (Rheinberger 1997). Technical objects provide a frame for the objects of inquiry, and involve the taken-for-granted equipment and tools. The focus of scientific work is on turning epistemic objects into technical objects. Though the empirical focus of this literature is narrower, with an interest in laboratory science involving molecules in the test tube or particle physics, it develops useful conceptual resources for understanding objects in knowledge practice within organizations. It has not, however, been linked with the discussion of boundary objects.

In order to understand knowledge practices more fully, we believe it would be productive to clarify these perspectives, linking definitions stemming from the different literatures. Table 1 summarises contemporary understandings of boundary object, epistemic object and technical object. By mapping what different researchers mean by 'object', we can begin to take a holistic view of what it is about objects that makes them such significant participants in knowledge work. For example, although boundary objects are now generally understood to be concrete, the concept was originally developed to explain objects of a more abstract nature. It is important to be clear about the nature of the object in question as this is consequential. Recently, when researchers have studied abstract objects such as atherosclerosis (Mol 2003) or alcoholic liver disease (Law and Singleton 2005) they have found them to be constituted as multiple concrete objects used in different practices. The ambiguities and confusions in the existing literature suggest interesting possibilities in reconceptualising and recasting objects and their role in knowledge work.

Accepted version, final publication: http://oss.sagepub.com/cgi/content/abstract/30/1/07 
Table 1: Key characteristics of boundary objects, epistemic objects and technical objects

\begin{tabular}{|c|c|c|c|}
\hline & \multirow{2}{*}{ Boundary objects } & \multicolumn{2}{|c|}{ Objects as part of an experimental system } \\
\hline & & Epistemic objects & Technical objects \\
\hline $\begin{array}{l}\text { Nature of } \\
\text { the object }\end{array}$ & $\begin{array}{l}\text { Concrete }^{*} \text { : There is one } \\
\text { object that is differently } \\
\text { interpreted and provides } \\
\text { a holding ground for } \\
\text { ideas for communication, } \\
\text { translation and } \\
\text { standardization of } \\
\text { meaning }\end{array}$ & $\begin{array}{c}\text { Abstract: Characterized } \\
\text { by lack and } \\
\text { incompleteness; } \\
\text { partially expressed in } \\
\text { multiple instantiations; } \\
\text { continuously evolving }\end{array}$ & $\begin{array}{l}\text { Concrete: Ready-to- } \\
\text { hand, complete and } \\
\text { unproblematic } \\
\text { instruments }\end{array}$ \\
\hline $\begin{array}{l}\text { Role over } \\
\text { time }\end{array}$ & $\begin{array}{l}\text { Stable: Stable enough to } \\
\text { enable coordination } \\
\text { across communities of } \\
\text { practice }\end{array}$ & $\begin{array}{l}\text { In-flux: Dynamic to } \\
\text { enable knowledge work } \\
\text { over time }\end{array}$ & $\begin{array}{c}\text { Static: Fixed and stable } \\
\text { tools }\end{array}$ \\
\hline $\begin{array}{l}\text { Subject- } \\
\text { object } \\
\text { relations }\end{array}$ & $\begin{array}{l}\text { Multiple: Used in direct, } \\
\text { cross boundary } \\
\text { interactions between } \\
\text { multiple actors }\end{array}$ & $\begin{array}{c}\text { Dyadic: Particular } \\
\text { instantiations are used } \\
\text { by the expert subject }\end{array}$ & $\begin{array}{c}\text { Dyadic: Concrete } \\
\text { instruments are used } \\
\text { by the expert subject }\end{array}$ \\
\hline
\end{tabular}

*here we draw on the recent literature on boundary objects (e.g. Carlile 2002; Carlile 2004; Henderson 1999)

\section{Relationships between different conceptions of 'objects'}

What are the relationships between the different conceptions of 'objects' shown in Table 1? As part of an experimental system, the notion of epistemic object is a large and generic conceptual category. It is overarching and future tense (e.g. a building being designed) and only partly expressed in material instantiations (e.g. a specific floor plan or a perspective sketch). The term technical object emphasizes the unquestioned, static nature of the material object once it is no longer evolved and changed through epistemic work. However a different characteristic of objects is highlighted through the term 'boundary object' which emphasizes the ability of an object to mediate knowledge across a boundary.

The relationships between these concepts point to the multi-dimensional nature of objects. An object can be at one and the same time a boundary object and a technical object, or a boundary object and an epistemic object. However, objects can also be used in epistemic work without spanning across boundaries of practice.

Accepted version, final publication: http://oss.sagepub.com/cgi/content/abstract/30/1/07 
A consequence of emphasizing boundaries between communities of practice is the focus on the use of objects across rather than within practices. The object gets located outside of, or at the periphery of practices. For example, Sapsed and Salter describe the difficulties of using project management tools and conclude that "Boundary objects, because of their marginal nature, are prone to be relegated to the edge of projects, which is after all where they belong" (Sapsed and Salter 2004: 1531). In contrast, we see objects as central to practices. We also do not see the objects that are used in coordination as necessarily peripheral to the epistemic work. Our questions are about which objects are central to co-ordination practices as well as which objects are central to practices of knowledge development.

Boundaries are a salient feature of the new product development context. In Carlile's (2002) work, communities of practice are clearly conceived of as functional groups within the organization. He describes how co-ordination across functions in the design review meetings can be fraught and at times conflictual. However, in many empirical contexts, communities of practice are less distinct and well defined than they are in the product development context. The boundaries are less salient. Within such trans-epistemic practices, object may be used in co-ordination of diverse knowledge-sets at the same time as knowledge development and learning.

There is a need to clarify the multiple dimensions of objects to understand their use in diverse organizational settings. We would expect the conceptual design setting of our study to differ from experimental science and engineering and new product development. Different dimensions of objects may be more or less significant in each setting. In the literatures, objects vary in the degree to which they are concrete or abstract; stable or in-flux; and associated with knowledge work within or across contexts and practices.

Though the term 'boundary objects' is used to describe concrete objects in the contemporary literature, in their foundational work, Star and Griesemer (1989) generalize and abstract the boundary object. They are thinking of representations, more than of physical artifacts. Drawing on their field work in the Natural History Research Museum, their examples of objects include species and sub-species of mammals and birds; the terrain of the state of California; physical factors in California's environment; and the 
habitat of animal species (Star and Griesemer 1989: 392). Objects in their work are described as mediating social relations within a practice through rules, common frames of reference and shared archives that enable productive collaboration. When these are embedded meaningfully into the local conditions and contexts of different stakeholders, the information processing which goes on in the museum can be managed in a way that allows for both heterogeneity and cooperation. Carlile $(2002 ; 2004)$ builds on the work of Star and Griesemer (1989) with his account of boundary objects. However, Carlile draws attention to objects in the collaborative efforts of new product development teams. In this context, he sees both the objects and the boundaries as more concrete. While it is in this sense that the term boundary object has become used in the organization studies literature, in contexts where there are less clearly defined or mutually exclusive communities the broader more abstract use of the term may still have much to offer.

In his work on the epistemic object, Rheinberger (1997) talks about spaces for representation, within which he sees graphemes or material traces. These are the concrete materials or objects of inquiry through which the epistemic object is manipulated and evolved. Thus visual representations bridge between the concrete and the abstract. They are themselves concrete but also represent the abstract thing. Whilst in the context of science such marks may be the outputs of the experimental system, which are changed as the system is manipulated, in other systems of inquiry they may be more deliberately made to convey meaning, as inputs to the epistemic work. The epistemic object is developed and manipulated as they are changed. Recent work on conceptual design activities (e.g. Barry and Rerup 2006; Yoo, Boland and Lyytinen 2006) has begun to emphasize this process, as well as its outputs. The images that are involved can be seen as having three constituent parts that always exist in hybrid forms: writing, pictures and notation (Elkins 1999). These deliberate marks (on paper, on the screen) are the focus of this paper. While others have noted the role of prototypes, scale models, and other forms of objects (e.g. Yoo, Boland and Lyytinen 2006), visual representations are certainly a significant, if not the major, way in which the abstract is linked with the concrete. As material instantiations, we see them as a crucial dimension of the epistemic object as it is with these that practitioners interact when they develop knowledge.

Accepted version, final publication: http://oss.sagepub.com/cgi/content/abstract/30/1/07 
Both in the literatures on boundary objects, and in the literatures on epistemic and technical objects there is the sense of the evolution of knowledge taking place through a 'conversation with materials' (Schön 1983). In discussing knowledge practice with epistemic objects, Knorr Cetina (2001; 1997) concentrates on the dynamic, even passionate, relationship between the subject and the object; between the expert and that which the incomplete 'epistemic thing' (Rheinberger 1997) is lacking. In her account, object-subject relations are dyadic. Theorists of boundary objects such as Henderson (1999) and Carlile $(2002 ; 2004)$ emphasize their role in enlisting the participation of multiple parties or actors. On this account, a plurality of intersubjective relations unfolds around the object of knowledge. Both the dyadic and the multi-actor view hint at an ontology of the object based on becoming rather than a fixed being. However, they differ with regard to whether the object itself is changed. Epistemic objects are defined in a way in which much of the thing-like character objects have in our everyday conception is thrown into question (Knorr Cetina 2001; 1997). Despite the mutability of boundary objects in relation to interpretations in the contexts of their use, there is no sense of unfolding or sequences of evolving representations. There is also no sense of lack or wanting on the part of the object. In both early and recent work, the boundary object is therefore somewhat stable, objectified and reified.

Epistemic objects are plural and evolving; they are multiple and unfold over time. The central characteristic of epistemic objects, as identified by Knorr Cetina (1997; 2001), is their openness, their 'lack in completeness of being' and their 'capacity to unfold indefinitely' (Knorr Cetina 2001: 181). The lack, uncertainty or indeterminacy of epistemic objects generates questions which turn into avenues for further exploration. Pursuing these avenues causes the epistemic object to evolve, satisfying some questions whilst opening up new ones. Lack precipitates unfolding. The object of knowledge as such is never actualized, never fully accomplished, but characterized instead by an 'unfolding ontology' (Knorr Cetina 2001: 182). It is defined by what it is not (or not yet) as much as by what it is.

As noted by Austin and Dars $\varnothing$ (2006): "Closure is a point of convergence that happens once or repeatedly in productive activity; it signifies an important shift from open to closed, from undetermined to determined, from undefined to defined". Once it 
has occurred objects are reified in their stability. They appear as instruments subconsciously absorbed into the practice of doing work. Technical objects are ready-tohand and unproblematic instruments that stand in contrast to the question-generating epistemic object (Knorr Cetina 1997: 10). The epistemic object, which is always ideal and unattainable, becomes a technical object. Such a move from open to closed is apparent in Carlile's empirical data, as he observes the work of moving an object from its current state to a required end state. Ken, who is head of sales in the valve manufacturer remarks of the object of his work, once complete, that its 'tidiness is an insulting disguise to all of the late nights, pain and frustration of getting there' (Carlile, 2002: 447). Ken's words could be taken to indicate the characteristic closed nature of the technical object once it has stopped being an epistemic object. Suddenly it is no longer the source of passionate labour and inquiry; late nights, pain and frustration.

Both in their closed forms, as technical objects, and in the open forms, as instantiations of the epistemic object, visual representations may embody a wide range of knowledge, extending from engineering-specific knowledge (Vincenti 1990) to aesthetic knowledge and sensitivity (Ewenstein and Whyte 2007). They are mobile and can be easily circulated so as to establish normative parameters and shared understanding (Latour 1986). At the same time, they can be read in a way that allows professionals with different perspectives to make sense of and contribute to the new product development process (Eckert and Boujut 2003; Henderson 1999). Thus theoretically they provide an example that illustrates the multi-dimensional nature of the object, and it is to our empirical data that we now turn to see how this is realised in practice.

\section{Setting and Method}

\subsection{The practice: research collaboration with Edward Cullinan Architects}

Founded in 1965, Edward Cullinan Architects is a professional service firm that offers architectural design services in the construction sector. It has a broad portfolio of architectural projects, which are frequently described in the architectural press and in monographs about the practice (Edward Cullinan Architects 1984; Hale 2005; Powell 1995).

Accepted version, final publication: http://oss.sagepub.com/cgi/content/abstract/30/1/07 
Within the firm there is a well established culture that puts the emphasis on the collective. Edward Cullinan Architects it is an unusual form of commercial organization: a partnership in which every member of staff can become a partner and be listed as such in the national database of companies. Partners do not hold equity in the company, but collectively they constitute the governing body of the company. The collective ethos of the practice is manifest in its office. Housed in an old warehouse in North London, in the period we studied, the ground floor of the building housed meeting rooms and a kitchen; and there was a single, open, office space upstairs in which all members of staff worked. Bays within this space provided a home for the various project teams.

\subsection{Data collection}

In our research we followed design practice on ongoing projects; observing and interviewing key members of staff, collecting secondary data and being involved in informal conversations regarding work. To minimize the disturbance this would cause, the first author conducted most of the in-depth observational work once the initial contact was made. Over a six month period in 2004, the first author spent approximately 130 hours (of 33 days) with the firm. During this time he was also involved in site visits and client meetings. Both authors visited the firm on multiple occasions, interviewing key members within the firm together and arranging for a number of feedback sessions with groups of architects interested in the research. Both authors frequently discussed their impressions from the field.

\subsection{The project: Royal Botanic Gardens at Kew Herbarium and Library Extension}

The project analyzed in this paper is the new Herbarium extension in the Royal Botanic Gardens at Kew in London. Though the project is fascinating in its own right, and fully deserves a detailed exposition in the architectural and engineering press, this is not our purpose here. We give only a simple overview to ground our analysis of the associated knowledge work. This project is an extension to one of the world's most important herbaria. It also houses a library and Kew Garden's information services department.

The planned herbarium extension connects to a wing of the existing herbarium and is intended to provide storage of dried plant specimens. The brief requests that provisions be made for storage 50 years into the future. The environment must be both Accepted version, final publication: http://oss.sagepub.com/cgi/content/abstract/30/1/07 
fire resistant to protect the collection and climate controlled to avoid pests such as bugs destroying the collection. The mass storage in movable compactor units, with fire protection of either two or four hours minimum and temperature regulation of about 15 degrees Celsius, places a number of specific structural, mechanical and spatial constraints on the design. Another demand of the brief is to provide not only space for the world's most expansive collection of dried specimens, but also a world-class reading room for the collection of library items and especially the rare books. This library requires a preservation room where items are restored or prepared for preservation. Librarians and botanists need offices and the entire Kew information services department and their graphic design and visualization technology will also need to be housed in the new building.

We studied the period from June 2004, the end of the inception and feasibility studies, when we observed discussions finalizing the report of these activities (known as the Royal Institute of British Architects (RIBA) Stage A/B); to the end of the conceptual design stage, which was formalized in the Stage C report in November 2004. This period constitutes a productive context for the exploration of knowledge-intensive practice, as it is when the overall design of the proposed building is developed. Developing the conceptual logic of the building involves intensive collaboration between clients, consulting engineers and the project architects. Table 2 shows the data-collection period in the context of real and projected timescales for the overall building project.

Table 2: Royal Botanic Gardens at Kew Herbarium and Library Extension Project Timeline

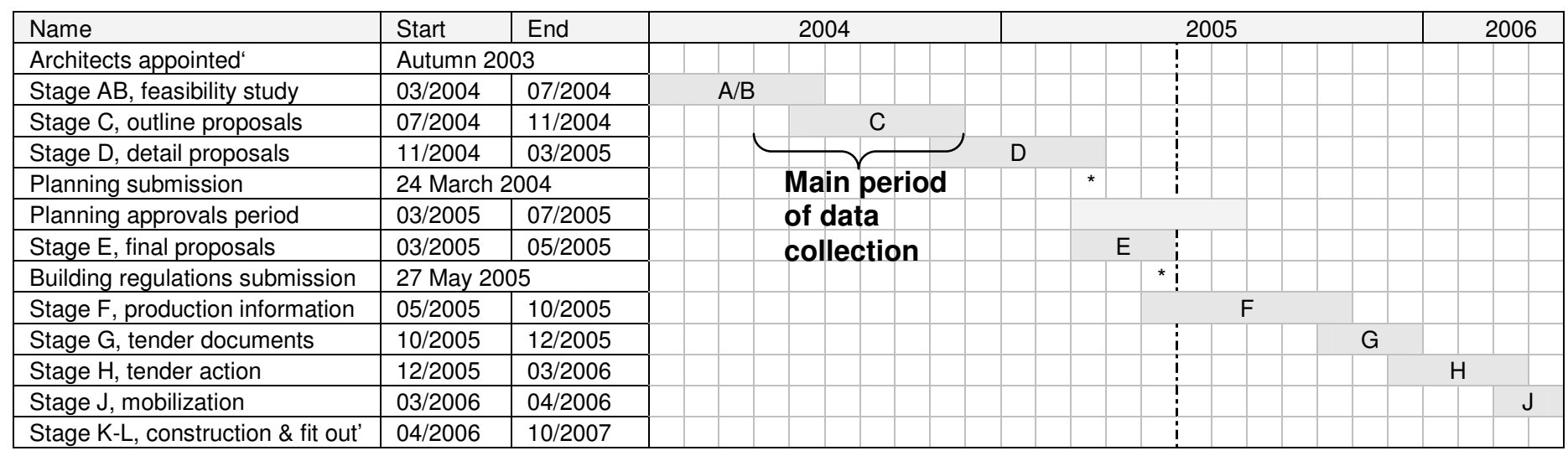

* Source: Stage E report (Edward Cullinan Architects 2005). The timeline is accurate to May 2005 when the project was pending planning permission. [Items marked' are not shown in the timeline]

Accepted version, final publication: http://oss.sagepub.com/cgi/content/abstract/30/1/07 
As we maintain an ongoing research relationship with Edward Cullinan Architects, we now know that the planning approvals process took longer than anticipated on this project. However this does not detract from the importance of their design work during the period of our data collection.

\subsection{Data analysis}

Informed by the methodological principle of 'grounded theory' (Glaser and Strauss 1967; Strauss and Corbin 1998), we moved iteratively between data collection and data analysis. We approached the ethnographic work with a number of conceptual categories formulated through a reading of existing literatures. In the course of collecting, organizing and interpreting our data, we refined our conceptual categories and returned to the field sites for further exploration. Whilst not all conceptual categories could be explored until 'theoretical saturation' (Glaser and Strauss 1967; Strauss and Corbin 1998), the iterative movement between analysis and data collection allowed for a continuous refining of our interpretations through ongoing engagement with and feedback from our research participants. Whilst retaining our focus on specific analytical concerns related to the use of visual materials, we also worked inductively to draw out emerging ideas, for example about the relation between the physical and digital instantiation of visual representations.

The analysis involved a careful reading and viewing of collected documents, photographic images, meeting and interview transcripts and field-notes. For example, we explored when and how terms such as 'knowledge', 'information', 'solution', 'change', 'update', 'evolve', 'develop' and 'coordinate' were used in conjunction with actual or spoken-about visual representations. In the course of repeated readings and viewings, this

provided one way to begin organizing copious amounts of data in regard to two fundamental questions guiding our research: 1) 'How are different options, solutions or versions arrived at? What role do collaboration and the use of visual representation play?' and, more specifically, 2) 'How are the contents in the Stage C report prepared by Edward Cullinan Architects arrived at in dialogue and through visual representation?' Given this frame of reference, the data were clustered around design episodes, and 
recurrent themes were identified across the compared clusters (in turn comprising of specific photographs, field-notes, documents and transcripts). In further field-work - and sometimes through the use of specific follow-up interviews - recurrent themes as well as emerging ideas were validated and explored in greater detail.

\section{Findings: The role of objects in multi-disciplinary knowledge practices}

Within the architectural design firm, knowledge intensive work is achieved through multiple interactions around visual representations. These interactions involve, pointing, drawing, annotating, reflecting and talking. Figure 1 shows snapshots of practices during the period we observed. They demonstrate how shared interaction takes place in a relatively informal context: the first photograph shows work alongside cups of tea and a plate of biscuits. It is intensely collaborative: the second photograph shows the architect's hand holding the tracing paper as the engineer draws. It also involves multiple iterations: the third photograph highlights the way in which drawings often become the focus for later epistemic work as dimensions are checked and they are themselves reworked.

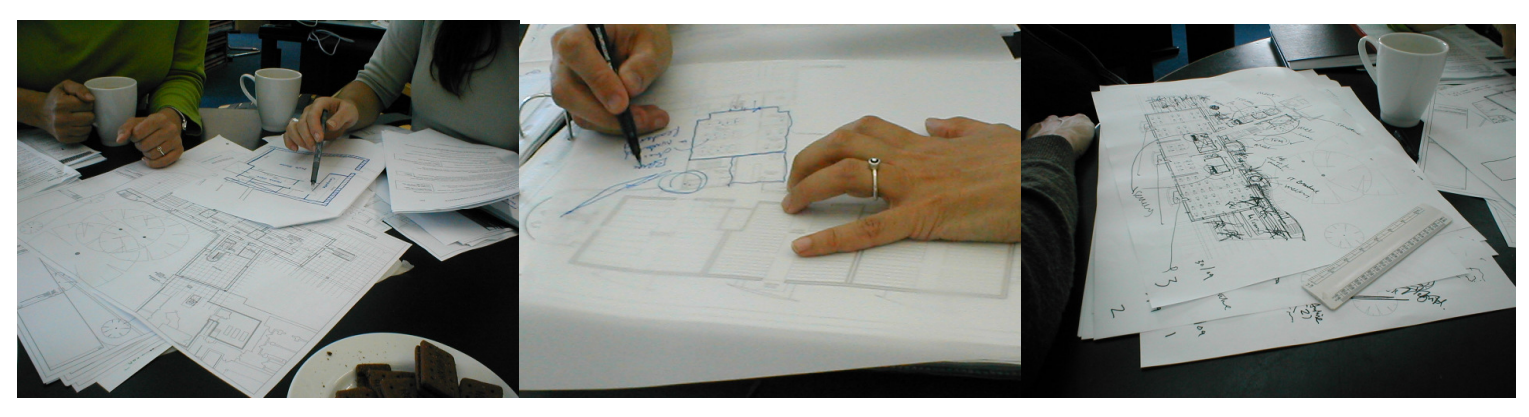

Figure 1: Selected images of work on the building during Stage C: showing the relatively informal context of the work, its collaborative nature and the way in which drawings become reworked.

As objects, visual representations are used in an inter-subjective way in knowledge work that develops both the project process and its product, the design for a building. They are used in process-oriented ways, for instance through the visualization of stage gates or through the symbolization of other sets of drawings, their location and status. However, our focus is on their use in product-oriented ways, in the design of the 
building. Here visual representations are used to communicate design ideas, to work collaboratively in problem-solving and to coordinate the inputs of different parties.

In this section, we explore the inter-subjective nature of knowledge work in design through a number of vignettes from the field. The field work concentrates on Stage C, during which: 'the work of the feasibility stage was expanded upon, but refinement of the broad brush moves began in parallel.' (Edward Cullinan Architects 2004: 1). This work culminates in the Stage $C$ report for the herbarium extension. We first use an analysis of this report to discuss the density of knowledge forms involved and the ways in which they are made visible (4.1). We then draw on the example of a catchup meeting between the lead architect, structural engineer and services engineer near the beginning of our study (end of Stage A/B) to draw attention to the trans-epistemic nature of the collaborative work around visual representations in this setting (4.2). We focus in on a later interaction between the architect and structural engineer, to explicate the role of drawings as technical objects and instantiations of the epistemic object in their collaborative engagement (4.3). Finally, we observe how visual representations can provide different perspectives on the same data-set; and how the development of design knowledge evolves through interactions with objects that unfold across both physical and digital instantiations (4.4).

\subsection{Density of knowledge forms in the Stage C report}

Stage reports capture the complexity and density of knowledge forms within the project. As objects representing knowledge, these reports comprise multiple modes of representation: writing, calculation, photography, 2D and 3D sketches and hard-line drawings in different styles and scales. They are created to mark out the arrival at a designated point, or stage-gate within the project, following RIBA recommended design stages and procedures. Stage reports summarize what activity has taken place and constitute a deliverable which clients can agree to and 'sign off'.

The report for Stage $\mathrm{C}$ was created at the end of the period we observed. It collates the outline proposal for the new building developed during this period. The stage is focused on developing a proposal while retaining the flexibility and choice in key areas where there are uncertainties. It follows on from the feasibility study (Stage A/B) and 
precedes the detailed proposals (Stage D). Figure 2 shows selected pages from the ninetyseven page document that forms the Stage C report. Although not fully fixed and immutable, it constitutes a relatively defined proposal for the Royal Botanic Gardens at Kew Herbarium and Library Extension. Sections of the text already existed in the fiftyeight page report for Stage A/B. However, while the Stage A/B report had a focus on goals, requirements, analysis, options and strategies; the focus of the Stage $\mathrm{C}$ report is more centrally on architectural, structural, environmental and landscape proposals.

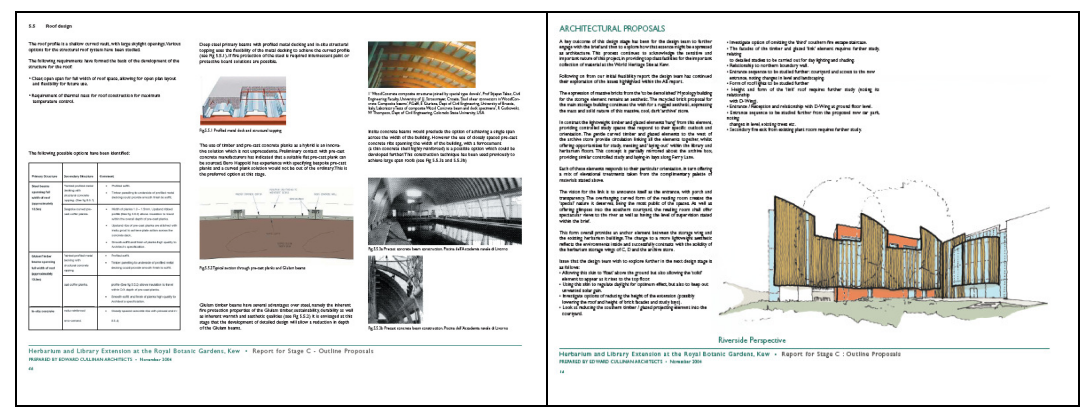

Figure 2: Two pages from the Stage $C$ report: a) structural considerations in the design of the roof; and $b$ ) the architectural proposals with a perspective of the proposed building.

Perhaps the most crucial set of knowledge to be held in focus in the report relates to the interests and requirements of the client. From their formative specifications flow the design ideas and solutions that are developed by the interdisciplinary project team. The project goals that are articulated include providing new storage for the backlog of existing botanical specimens and library books; providing a space for 50 years of herbarium accessions, and providing for 30-50 years of library acquisitions. More specifically, the stage report articulates that accommodating the collection involves careful control of the internal environment to reduce the risks of damage to the collection. Further specifications articulate the need for offices and workspaces, decontamination facilities for plant specimens and a restoration facility for the library collection. These objectives were largely articulated in the report for Stage $\mathrm{A} / \mathrm{B}$, but have been revised in Stage $\mathrm{C}$ to include a reference to making the car park a positive part of the visitor 
experience. Both as predefined by the client and as emergent in the course of the project taking shape, they serve as overarching organizing principles which structure the activities of architects and consultants (structural engineering, building and environmental services, etc.).

Particular professional communities generate and communicate their project knowledge in response to this wider frame of reference. For the roof design, for example, the structural proposals in the Stage $\mathrm{C}$ report specify a shallow curved vault with skylight openings, in a page shown in Figure 2. Three options are introduced and discussed, namely the use of steel beams, glulam (glue laminated) timber beams and pre-cast concrete beams. These options meet the following requirements: 'Clear, open span for full width of roof space, allowing for open plan layout and flexibility for future use' and 'Requirement of thermal mass for roof construction for maximum temperature control' (Edward Cullinan Architects 2004). The structural engineers have also attached a set of drawings (plan and section) that represent a proposed roof arrangement indicating the dimension and position of the beams. This technical and highly codified information sits alongside quite distinct, yet equally valid and significant knowledge, namely aesthetic knowledge.

The aesthetic knowledge developed is both visualized and articulated in the text, as shown in Figure 2. The architects write that a key outcome of this design stage has been to further engage with the brief provided by the client and then 'to explore how that essence might be expressed as architecture' (Edward Cullinan Architects 2004: 14). This exploration of architectural form demands non-verbal and sense-based modes of knowing (Ewenstein and Whyte 2007; Strati 1999). The development and application of aesthetic knowledge also becomes apparent in the following passage:

\footnotetext{
'The recycled brick proposal for the main storage building continues the wish for a rugged aesthetic, expressing the mass and solid nature of this massive, cool, dark 'archive' store. In contrast the lightweight timber and glazed elements 'hang' from this element, providing controlled study spaces that respond to their specific outlook and orientation. The gentle curved timber and glazed elements to the west of the archive store provide circulation linking all the elements together [...]' (Edward Cullinan Architects 2004: 14).
}

This passage describes a 'rugged aesthetic', massive and solid, in contrast with 'gentle' and 'lightweight' elements. An aesthetic sensitivity and competence that informs the Accepted version, final publication: http://oss.sagepub.com/cgi/content/abstract/30/1/07 
design is expressed here. Further to this text, a number of perspective drawings provide an indication of the feel of the space to be created, the way it will look and lend itself to sensual experience.

\subsection{The nature of the trans-epistemic collaborative work around visual representations}

The Kew Herbarium extension involves the independent and collaborative work of architects (Edward Cullinan Architects), environmental and services engineers, structural engineers, quantity surveyors, external environment and landscape consultants, traffic engineers and, of course, the briefing contributions offered by the client at Kew Gardens. Further stakeholders such as town planners and organizations like English Heritage are also involved and more participants will come on-stream once the project is taken on-site. These different parties represent distinct communities and cultures. Knowledge practice in the context of this project involves cross-functional teams that cut across organizational boundaries. However, we often observed very close forms of collaboration across professional disciplines.

Near the start of our ethnographic study (at the end of June), for instance, there was an hour-long meeting between the project architect, the structural engineer and a building services engineer to co-ordinate their inputs to the earlier stage report $(\mathrm{A} / \mathrm{B})$ and to further discuss the issue of car-parking. This took place around a large table in a meeting room in the architectural practice with mugs of tea. The project architect had been to talk with the client in the morning and the meeting was partly to 'fill in' the other consultants and to see what needed to be done.

For the first five minutes the three participants talked informally about recent meetings and chatted about the opinions of people in the industry that they all knew. These included concerns about the fire safety of existing buildings and worries about the Prince of Wales, who has strong views on architecture. The mood was friendly and there was laughter.

The architect then reminds the others that they have talked about car-parking and articulates some of the options and their related problems. She has the draft report laid out on the table in front of her, printed in colour on large (A2) sheets, which are loosely bound. The structural engineer proposes that she should talk about the current plan for 
car-parking, which she then articulates, along with a number of related alternatives. He sits next to her and has a pad of ruled paper, on which he is taking notes. In the middle of the table there is a colour print-out of the site showing the car-park layout, over which is a felt-tip sketch on tracing paper. This sketch has multiple lines, as ideas have been worked out and revised on it. It was made in the earlier meeting and the architect is now pointing to it and explaining the conversations and rationale to the other consultants.

The conversation about car parking is fundamental to the design of the building, as the need for car-parking space will determine the location of the building on the site. However, there are also internal factors that constraint the design of the building, and as the team tries to understand the key uncertainties the conversation flips from a discussion of the landscaping to a discussion of the interior. The architect sums up the three main options for car parking, and then they talk in detail about the potential to convert the function of one of the proposed internal spaces should there be a requirement for more office-space in the future. The building services engineer says, 'You know the reality is it'll make a very simple space to convert into offices.' They jointly consider what can be done to cool the space in summer by using skylights or vents in the roof to increase the occupancy. Hence the conversation around the drawings moves across a diverse range of knowledge sets and issues as the design work progresses.

Towards the end of the meeting they are summing up and deciding on what actions they need to take. The architect mentions the schedule: The Stage A/B report probably won't be shown to the board of trustees until September, and she needs to figure out the printing date, the presentation date and the whole series of Stage $\mathrm{C}$ meetings to follow on. They discuss when they are away on summer holidays. There is still some work to do on the text of the report, which is interspersed around the visual representations and explains them. The following exchange provides an indication of the almost intimate way of working together across organizational boundaries.

Str. eng.: $\quad$ I think it'd be useful if you send me my two pages, because at the moment I think we should either make it smaller or just sort of make it more compatible to the sort of the style that you've got in the rest of the report. I think I can probably work them up again. Last Wednesday, I didn't give myself lots of time. I can add a bit more to that section.

Lead arch.: $\quad$ And then we need to sort out how we're going to put the information for this new bit of work together.

Serv. Eng.: $\quad$ To me it sounds like we should be doing combined commentary.

Accepted version, final publication: http://oss.sagepub.com/cgi/content/abstract/30/1/07 
Lead arch.: $\quad$ Yes, that's what it feels like.

The service engineer states that this is quite a complicated bit of design, but the structural engineer points out that there are three options for the basic building shape, each of which could be described with 'a few bullet points from each of us'. The lead architect then suggests going back to the site:

Lead arch.: $\quad$ So, I'd say the first thing that we need to do is to all go out there again together, and look, walk around the buildings, the existing bits.

Serv. eng.: $\quad$ Yes.

Str. eng.: $\quad$ Yes.

Lead arch.: $\quad$ And we can talk, and talk and walk.

Serv. eng.: Yes.

Lead arch.: $\quad$ And take pics, and...

Str. eng.: $\quad$ Could do it together...

Lead arch.: What's your time like this week? So that we have to do that sooner rather than...

Following the interaction above, they arrange to meet up on the train the day after next, and then the consultants excuse themselves as they have to rush off and the meeting breaks up.

The site 'the buildings, the existing bits' is clearly an important reference in this type of work - important enough to make the trip out to see it at relatively short notice. However, it is visual representations of the site and the design that have been the main focus of the knowledge work in this meeting. The colour print-out of the car-park layout, which is overlaid by a tracing paper sketch and sits in the centre of the table is shown in Figure 3. In an earlier meeting the colour print-out had served as a technical object, which allowed the overlaid tracing paper sketch to become the focus of epistemic work as it was changed and updated in conversation. The photo in Figure 3 was taken during the meeting and shows the architect pointing to the sketch while explaining it to the structural engineer and building services engineer. In this context, the combined image - the feltpen sketch and the colour print-out - serve as a focal object, mediating knowledge from the different participants.

Accepted version, final publication: http://oss.sagepub.com/cgi/content/abstract/30/1/07 


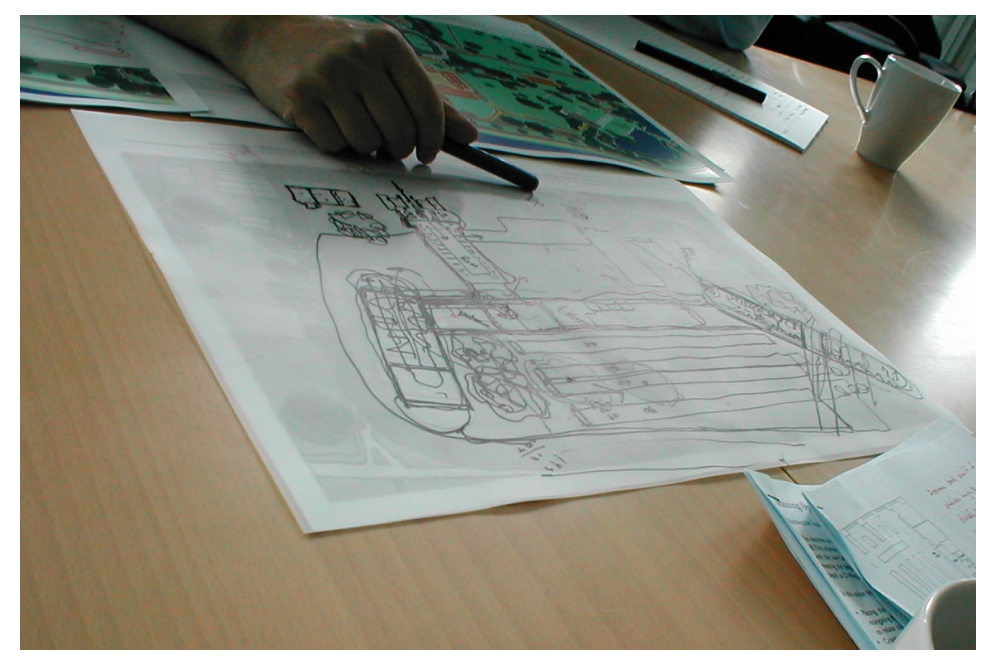

Figure 3: The architect points to the overlaid sketch as she explains the options for the design of the car-park and the location of the new building on the site.

Given the integrated nature of complex construction projects, design knowledge is developed in close coordination and negotiation with other members of the crossfunctional design team. However, the mode of co-ordination here is different from that which is often described in the literatures on boundary objects. The representatives of different epistemic communities work together on problems in a shared way. They often seek to develop shared understanding of problems rather than interacting through more formal roles and responsibilities. All three participants in the meeting interact throughout the discussion, providing encouragements and making jokes when they are not inputting directly into the knowledge work.

\subsection{Epistemic objects in collaborative knowledge practice}

In the fieldwork conducted, the characteristic openness or incompleteness of epistemic objects could be observed in numerous instances in which visual materials were used. While it is a particular hallmark of early-stage conceptual design, such as that in the catch-up meeting, we found instances of such openness and malleability throughout the design process. A good example involves the hand-drawn, heavily marked-up sketch, which formed part of the competition project discussed in detail in Ewenstein and Whyte (2007). This serves here as an empirical indication of epistemic objects in design. Commenting on the layers of inscription turning the sketch into a veritable palimpsest of ideas and exploratory markings, senior architect and partner Johnny explains: 
In that green sketch here, you've got more emphasis on parts which are felt to be more important or more worked on. Or maybe have more questions; because the sketch is suggesting, "I don't know exactly where that line is, maybe it's there, maybe it's there" (emphasis added).

The sketch begins to embody design knowledge. However, it is not fully formed or defined; instead, it raises questions. It acquires an almost agential role, becoming a nonhuman 'actant' (Law 1992). This is mirrored in the active voice that the sketch receives in Johnny's account. The sketch as epistemic object actively draws attention to its own incompleteness and poses the question back to the practitioner for further development. Where, indeed, should that line be drawn? If a ready answer is not at hand, the designer responds by trying a number of lines and assessing their impact on the design once drawn. Design here takes the shape of exploration or inquiry. The drawing is an active participant in a process of exploratory, projective reflection. It does not simply depict or represent the previous reflections of the designer or designers. Thus the important role visual representations play as knowledge objects is not just on account of their capacity to embed or inscribe knowledge. Inscribing, embedding and containing is only part of the story; the other is lacking, wanting and unfolding in uncharted directions.

Intrinsically, epistemic objects raise questions. But how can they be modified and used collaboratively to find answers, to develop knowledge jointly? The following meeting on the Herbarium project is used to further understanding of visual representations in their various roles as technical objects and instantiations of epistemic objects.

It is now early October and the structural engineer and lead architect are back around the table, accompanied by younger colleagues. The design challenge is to find a structural solution for the roof of the planned herbarium extension. In the long term, beyond 15-20 years of usage, the office space is also envisioned as plant storage. In this scenario, the walls partitioning the different storage compartments can function as structural elements. In the short term, however, a design idea needs to address how the roof structure will be dealt with in an open-plan environment. As issues are raised and explored during the meeting, different representations are used in conjunction with each other.

Accepted version, final publication: http://oss.sagepub.com/cgi/content/abstract/30/1/07 
The meeting takes place in the offices of the structural engineer across a table strewn with visual representations. Sections offer views of the roof and skylights from the side and from the front, showing the points of intersection between the roof and the sidewalls. Plans of the building's floors are in use as well as various sheets of marked and unmarked tracing paper. Rulers, markers, coloured pens and pencils complete the picture.
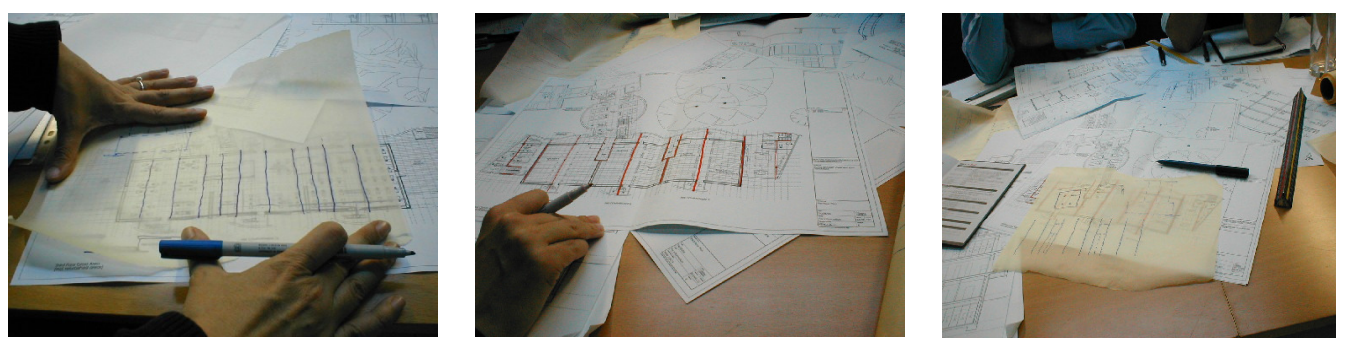

Figure 4: tracing paper used to define a suitable beam arrangement for the floor above (left); load-bearing elements highlighted in red (centre) and multiple discarded objects of inquiry (right).

The meeting starts with a discussion of the newest issue of the plans and a brief discussion of the stairs. Pointing to the plans, the structural engineer says that anything that curves may worry the quantity surveyor, responsible for cost-control, but that rectangular stuff is fine. They then talk about roof lights and the advantages and disadvantages of various alternative structural solutions for the roof. The structural engineer talks about material properties, for instance the weight and thermal mass of concrete. The architect expresses preferences in terms of the look and feel of the proposed building. She thinks concrete could be 'too chunky' if it meant there would not be much window left. Later she explained that,

one of the solutions we had for this were these very expensive pre-cast units with just steel bar at the bottom of the arch to tie it together. [...] Structurally and as an element it looked quite an elegant thing - we realized in the space, where you also had light fittings and everything else, that it was going to look incredibly busy if you had 30 steel ties running across the ceiling plus your light fittings and everything else. And that was one of the main reasons why we moved away from that, plus cost.

Her explanation suggests that the drawings hide as well as reveal information and need constant interpretation. In the drawings the pre-cast units looked elegant, but when they 
thought about what it would be like to inhabit the space they could foresee a number of problems. During the discussion, they consider the alternatives: using glulam beams or steel beams. They begin to draw to experiment with the alternatives.

The top floor plan, for instance, is used in conjunction with a plan of the floor just below in one design episode. This representation is not modified further in the discussion. It now serves as a technical object, providing a stable reference point. This allows the architect to explore how beams under the roof need to be spaced for structural purposes. This is affected by the material that they choose for the structure. They are trying to rationalize the structural base, and she says that they have to do a few studies of it. On sheets of tracing paper, proposed arrangements of such beams are drawn by the architect with reference to the printed plans (see Figure 4). In conversation with the structural engineer, she wants to work out the exact spacing of the beams. She adds dimensional information to the sketch and considers various options.

Referring, pointing to and touching the visual representation, the engineer expresses his knowledge about the possible and suitable positions of the beams which the architect is sketching onto tracing paper. As an epistemic object, the visual representation used here poses a question or a problem: how can a suitable arrangement of beams to carry the roof be found? As an object it elicits the knowledge of both the architect and the structural engineer. They explore the key structural elements such as (horizontal) beams and how they bear the weight through the different floors of the building. On one floor plan these structural elements are highlighted in red. In an ongoing and dynamic way, new questions are put to the architect and the engineer respectively as various drawings are developed and the design progressed.

There is a cantilevered section of the first floor, and the focus of the conversation shifts towards that. The engineer consults a book, the "Economic Concrete Frame Elements", to get further information on requirements for beam depth, deflection, etc. The architect asks if the column position can be moved to accommodate furniture and walling space, however the column is needed as the area she is talking about is too long a distance to span without a column. The architect then returns to draw and discuss the section of the whole building including the roof. They are circling around the question of the materials to use, but as there are a number of uncertainties remaining the participants 
are reluctant to make a choice based on the available information. The three options for materials discussed in this meeting are refined and presented in the Stage $\mathrm{C}$ report.

There are questions raised here about what it means for something to be an epistemic object. In this work is it the building that is the epistemic object or is it the beams? The focus continuously shifts between the representation and the building it proposes. Looking at the drawings, the architect told us:

You've got these three boxes, which eventually they want to be herbarium storage, with partitions that go up to the roof ...

Her words hint at the ambiguity over what is the object. She starts by describing features that the drawing shows - 'you've got these three boxes' - but then quickly shifts on to talk about what they want to be.

\subsection{Evolving the design: Unfolding objects from physical into digital forms and back}

As we followed the work of the architects across a number of meetings and design episodes new questions arose: How is the process of design progression achieved in detail? How is evolving knowledge embodied in new sets of representations? Sheets of tracing paper and images annotated in design team meetings, such as the roof design meeting between architect and structural engineer, contain a residue of thought-processes. These instances of knowing are reinscribed in new drawings and representations that are, again, circulated across the design team. This process involves CAD technology and extends the definition of what we might see as the object. Hardcopy prints and freehand sketches on paper are physical artifacts central to different types of knowledge practice. However, they are connected to digital drawing files which are worked on in conjunction.

For instance, consider how the architects, structural engineers and building services engineers develop their respective proposals for the architectural layout, general structural arrangement and ventilation system. The versions that are used in the Stage C report are shown in Figure 5. As objects with 'co-incident boundaries' (Star and Griesemer 1989: 392) they can be seen as boundary objects: They are relatively stable versions of the drawings, which reveal the different knowledge work of the professionals involved.

Accepted version, final publication: http://oss.sagepub.com/cgi/content/abstract/30/1/07 

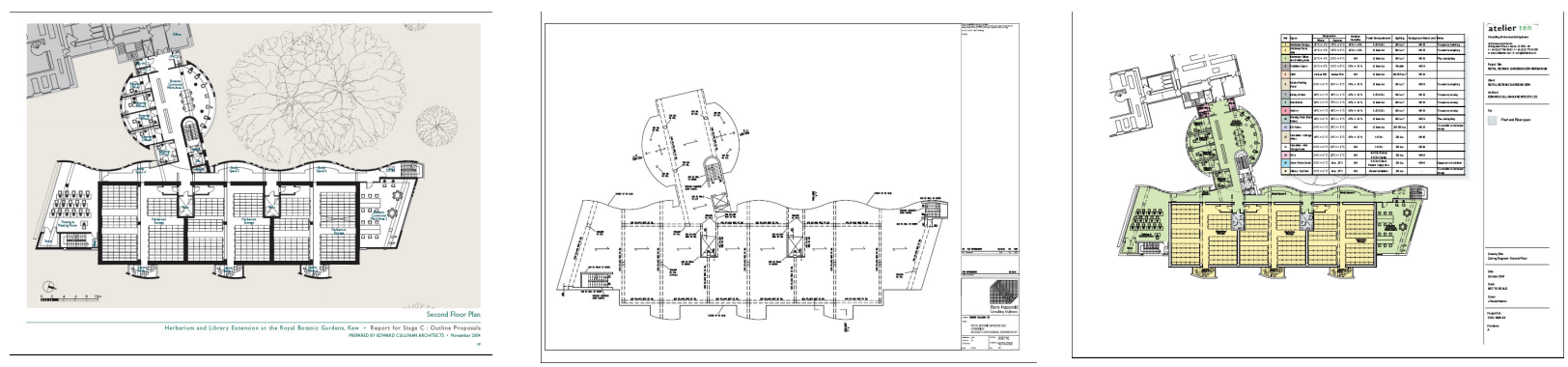

Figure 5: Three pages from the Stage C report: a) architects' drawing of second floor plan, structural engineers' drawing of second floor and environmental engineers' second floor plan of ventilation system.

These various drawings were developed by modifying and resaving digital drawing files on the computers. In the process of working up these different versions, a multi-layered CAD plan of the second floor with layers of information that can be made visible or absent by using a function called 'cross-referencing' was circulated by the architects. The other consultants could turn off layers containing information not immediately relevant or even obstructive to their own specialist inputs (e.g. proposed furniture arrangements). The images indicate the appropriation of the drawing file by three distinct occupational communities, adding their respective knowledge forms. The structural and building services engineers could develop and embed their solutions amongst layers that are related to their immediate work. In practice, cross-disciplinary knowledge development occurs through the use of physical artifacts. But it also occurs through multi-layered drawing files that embody strata of distinct information, inviting selective interpretation and contribution. The objects in our study must be understood to extend from the physical into the digital, facilitating the selective appropriation of meaning and contribution of knowledge.

The relationship between the individual designer and the representation on their computer screen is inherently dyadic. It was less easy for us to observe this form of knowledge work than it was to observe the meetings and interactions. Figure 6 provides a snapshot of an annotated drawing beside a designer's computer. The information on this drawing will be used as a reference as epistemic work is conducted on the screen. In this instance, from August 2004, particular user requirements are being translated into design solutions. The design drawing shows the basement, and on it the annotations indicate, for example, that the photographer would like high-level windows or that there is a concern that this design involves too much circulation space.

Accepted version, final publication: http://oss.sagepub.com/cgi/content/abstract/30/1/07 


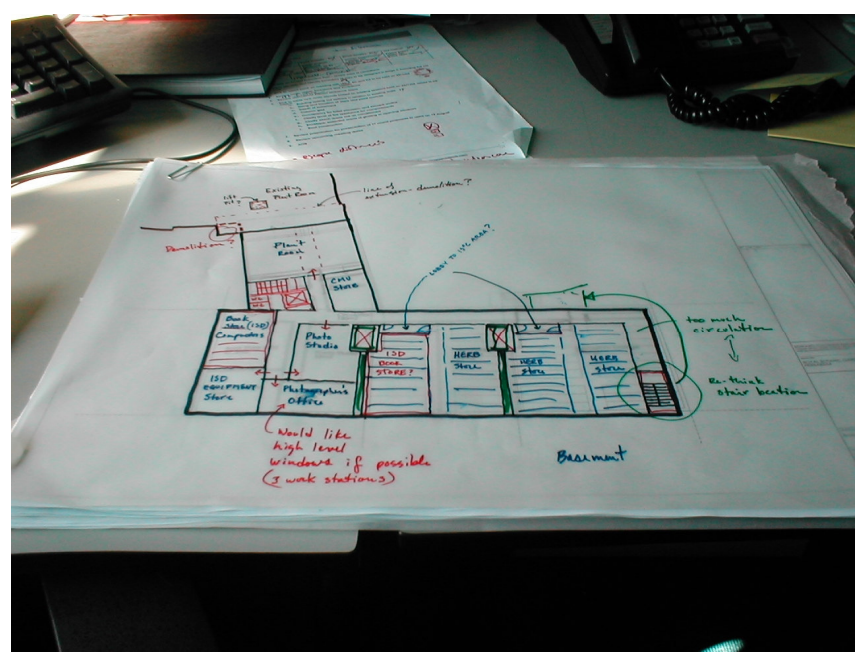

Figure 6: a plan marked up to show user requirements, near an architect's computer in the office.

Thus different inputs from expert designers and end-users alike are elicited and integrated through the use of visual representations. Drawings, sketches, plans or sections therefore act as devices to 'conscript' or enlist the contribution of others (Henderson 1999). This can be a very subtle process of making apparent gaps, problems or uncertainties to be resolved by specific actors. In other instances, they contain a direct invitation for members of another epistemic community to contribute their knowledge in the same way as a comment on a document might. For example, one drawing in the Stage $\mathrm{C}$ report shows the building services and is annotated with the words 'Note: Plantroom layout requires architectural \& structural coordination during next design phase. Current layout is not adequate'. In a very explicit way this representation calls upon the input of other stakeholders.

\section{Discussion and concluding remarks}

Our theoretical and empirical work suggests that objects are multi-dimensional. By articulating dimensions to objects (stable-in-flux; abstract-concrete; and used within and across practices) we begin to clarify the kinds of roles that objects play in knowledge intensive work. The epistemic object is a broad abstract phenomenon, partially captured within a visual representation, which is an instantiation of it. In the context we studied, we observe how visual representations are used to manipulate epistemic objects. They are 
used to stabilise some aspects of design and evolve others. Through this work the project knowledge develops and the concept of the building is defined and refined.

In this setting, relations with the object are multiple rather than dyadic. The contributions of members of different professional communities are elicited because visual representations actively demand development or definition. As evolving epistemic objects, visual representations raise questions whilst answering others (Knorr Cetina 1997; 2001). In multi-functional teams, elements of visual representations are differently relevant to different actors. Meanings shift, supporting different interpretations as ambiguous working drawings rely on the beholder to complete the meaning of the representation; and as they contain multiple layers of (possibly precise) information and signification that carry different implications for different actors, depending on their context and agenda.

By contrast with recent descriptions of boundary objects, which mediate knowledge work in particular instances at given boundaries, these objects reflect a knowledge development process that proceeds in an ongoing and dialogical way; embodying a lack, raising a question, begging an answer, unfolding, developing a lack elsewhere, raising new questions, and so on. While the boundary object is relatively stable and concrete, the epistemic object is relatively dynamic and abstract, comprising cascades of unfolding instantiations. In the context we observed, conceptual design knowledge is developed not so much through relatively stable boundary objects but through constantly unfolding epistemic objects. In their epistemic role, circulating representations are not so much immutable mobiles (Latour 1986), establishing normative standards or accepted 'truths', as essentially mutable objects, characterized by their tendency to unfold or evolve.

However, not all representations evolve at once. In particular design episodes that revolve around a specific issue, multiple representations are used side by side. As certain representations are modified and evolved, others are being used as technical objects to provide reference points. Representations such as the plan showing key structural elements below the floor that the architect and engineer were working on are not problematized; they are held constant. Temporarily, within the context of a specific 
episode, the knowledge represented in these images is used instrumentally and treated as given.

By articulating the multi-dimensional nature of objects this work also sets out a new agenda for research. There is much more to be learned about the various dimensions of objects used in practice. Unlike in the scientific laboratory, in the architectural practice it may not be apparent what the epistemic object is and what the technical object, except in particular fleeting encounters. We observe a shared ownership of materials, with multiple hybrid forms of visual representation worked on directly, or sketched over, in a range of formal and informal meetings. This is different from the pattern of interaction observed in high-tech product development, where team members have clear ownership of, and responsibilities for, particular visual materials and bringing these to the regular scheduled meetings (Whyte et al. submitted).

Our work has a number of implications for understanding the role of objects in how knowledge-intensive work is achieved in practice. It reflects the dialogical nature of collective knowledge work in this context (Tsoukas 1996). An analytical focus on objects in organizations throws into relief the material conditions, symbolic contexts and social relations in which practice is situated. A focus on objects can reveal the iterative, even dialogical processes through which knowledge is developed by both subjects and objects as agents. Both are inquiring, answering and raising new questions in their own ways. But it is this agency of epistemic objects - their capacity to generate questions and to open up different issues to different stakeholders - that can make them difficult to manage. While they were central to knowledge work in the organizational contexts we observed, epistemic objects can also become 'unruly' and their meanings difficult to contain. Practitioners and managers should be aware of this as they communicate with each other and with external stakeholders.

\section{Acknowledgements and author biographies}

[To be added] 


\section{References}

Austin, Robert and Lotte Dars $\varnothing$

2006 'A Framework for Examining the Concept of Closure in Innovation Process'. in Art of Management and Organization. Krakow.

Barry, David, and Claus Rerup

2006 'Going Mobile: Aesthetic Design Considerations from Calder and the Constructivists'. Organization Science 17/2: 262-276.

Bechky, Beth A.

2003 'Object lessons: Workplace artifacts as representations of occupational jurisdiction'. American Journal of Sociology 109/3: 720-752.

Beck, Ulrich

1992 Risk Society. London: Sage.

Carlile, P.R.

2002 'A pragmatic view of knowledge and boundaries: boundary objects in new product development'. Organization Science 13/4: 442-455.

Carlile, Paul R.

2004 'Transferring, translating, and transforming: An integrative framework for managing knowledge across boundaries'. Organization Science 15/5: 555-568.

D'Adderio, Luciana

2001 'Crafting the virtual prototype: how firms integrate knowledge and capabilities across organisational boundaries'. Research Policy 30/9: 1409-1424.

D'Adderio, Luciana

2003 'Configuring software, reconfiguring memories: the influence of integrated systems on the reproduction of knowledge and routines'. Industrial and Corporate Change 12/2: 321 - 350 .

Eckert, Claudia, and Jean-Francois Boujut

2003 'The role of objects in design co-operation: communication through physical or virtual objects'. Computer Supported Cooperative Work 12/2: 145-151.

Edward Cullinan Architects

1984 Edward Cullinan Architects. London: RIBA Publications Limited.

Edward Cullinan Architects

2004 Herbarium and library extension at the Royal Botanic Gardens, Kew: report for Stage C (Outline Proposals). London: unpublished report.

Accepted version, final publication: http://oss.sagepub.com/cgi/content/abstract/30/1/07 
Edward Cullinan Architects

2005 Herbarium and library extension at the Royal Botanic Gardens, Kew: report for Stage E (Final Proposals). London: unpublished report.

Elkins, James

1999 The Domain of Images. Ithaca: Cornell University Press.

Engeström, Y., and F. Blackler

2005 'Special issue: On the life of the object'. Organization 12/3.

Ewenstein, Boris, and Jennifer Whyte

2007 'Beyond words: aesthetic knowledge and knowing in organizations'. Organisation Studies 28/5.

Giddens, Anthony

1990 The consequences of modernity. Cambridge: Polity.

Glaser, Barney G., and Anselm L. Strauss

1967 The discovery of grounded theory. London: Weidenfeld and Nicolson.

Hale, Jonathan

2005 Ends, middles, beginnings. London: Blackdog Publishing.

Heath, Christian, and Graham Button

2002 'Editorial Introduction. Special Issue: Workplace Studies'. British Journal of Sociology 53/2: 157-161.

Heath, Christian, Hubert Knoblauch, and Paul Luff

2000 'Technology and social interaction: the emergence of 'workplace studies". British Journal of Sociology 51/2: 299-320.

Henderson, Katherine

1991 'Flexible Sketches and Inflexible Data Bases: Visual Communication, Conscription Devices, and Boundary Objects in Design Engineering'. Science, Technology, \& Human Values 16/4: 448 - 473.

Henderson, Katherine

1999 On Line and On Paper: Visual representations, visual culture and computer graphics in design engineering. Boston: MIT Press.

Knorr Cetina, Karin

1997 'Sociality with objects: social relations in postsocial knowledge societies'. Theory, Culture and Society 14/4: 1-30.

Accepted version, final publication: http://oss.sagepub.com/cgi/content/abstract/30/1/07 
Knorr Cetina, Karin

2001 'Objectual practice'. in The practice turn in contemporary theory, edited by Theodore R. Schatzki, Karin Knorr Cetina, and Eike von Savigny. London: Routledge Pp. 175-188.

Latour, Bruno

1986 'Visualization and cognition: thinking with eyes and hands'. Knowledge and Society: Studies in the Sociology of Culture Past and Present 6: 1-40.

Law, John

1992 'Notes on the theory of the actor-network: Ordering, strategy and heterogeneity'. Systems Practice 5/4: 379-393.

Law, John, and Vicky Singleton

2005 'Object Lessons'. Organization 12/3: 331-355.

Mol, Annemarie

2003 The body multiple: ontology in medical practice. Durham: Duke University Press.

Orr, Julian

1996 Talking about Machines: ILR Press, Cornell University.

Powell, Kenneth

1995 Edward Cullinan Architects. London: Academy Editions.

Rheinberger, Hans-Jörg

1997 Toward a history of epistemic things: synthesizing proteins in the test tube. Stanford: Stanford University Press.

Sapsed, J., J. Bessant, D. Partington, D. Tranfield, and M. Young 2002 'Teamworking and knowledge management: a review of converging themes'. International Journal of Management Reviews 4/1: 71-85.

Sapsed, Jonathan, and Ammon Salter

2004 'Postcards from the edge: Local communities, global programs and boundary objects'. Organization Studies 25/9: 1515-1534.

Schatzki, Theodore R., Karin Knorr Cetina, and Eike von Savigny (Eds.) 2001 The practice turn in contemporary theory. London: Routledge.

Schatzki, Theodore R.

2006 'On Organizations as they Happen.' Organization Studies, 27: 1863-1873.

Accepted version, final publication: http://oss.sagepub.com/cgi/content/abstract/30/1/07 
Schön, D.A.

1983 The Reflective Practioner: How professionals think in action: Basic Books.

Star, Susan Leigh

1989 'The structure of ill-structured solutions: boundary objects and heterogeneous distributed problem solving'. Distributed Artificial Intelligence 329, 2: 37-54.

Strati, A.

1999 Organization and Aesthetics. London: Sage.

Strauss, Anselm L., and Juliet Corbin

1998 Basics of qualitative research: techniques and procedures for developing grounded theory. London: Sage.

Tsoukas, H.

1996 'The firm as a distributed knowledge system: A constructionist approach'. Strategic Management Journal 17: 11-25.

Tsoukas, Haridimos

2006 'Talking About Machines-Tenth Anniversary'. Organization Studies 27: 17411742.

Vincenti, Walter G.

1990 What engineers know and how they know it. Baltimore: John Hopkins University Press.

Whyte, Jennifer, Boris Ewenstein, Michael Hales, and Joe Tidd

submitted 'Visualizing Knowledge in Project-Based Work'. Long Range Planning.

Yakura, Elaine K.

2002 'Charting Time: Timelines as temporary boundary objects'. Academy of Management Journal 45/5: 956-970.

Yanow, Dvora

2000 'Seeing Organizational Learning: A Cultural View'. Organization 7/2: 247-268.

Yoo, Youngjin, Richard J. Boland, and Kalle. Lyytinen

2006 'From Organization Design to Organization Designing'. Organization Science 17/2: 215-229.

Accepted version, final publication: http://oss.sagepub.com/cgi/content/abstract/30/1/07 